headaches, abdominal pains, dry coughs, diarrhoea, vomiting, and blistered mouths. More information is needed about the hazards of cyanobacterial toxins to health.

We thank Drs S M Brown and J Ward for their help in compiling this report.

1 Codd GA, Bell SG, Brooks WP. Cyanobacterial toxins in water. Water Science and Technology 1989;21:1-13.
2 Carmichael WW. Toxins of freshwater algae. In: Tu AT, ed. Handbook of natural toxins. Vol 3. New York: Dekker, 1988:121-47.

3 Brooks WP, Codd GA. Extraction and purification of toxic peptides from natural blooms and laboratory isolates of the cyanobacterium Microcystis aeruginosa. Letters in Applied Microbiology 1986;2:1-3.

4 Falconer IR, Jackson ARB, Runnegar MTC. Liver pathology in mice in poisoning by the blue-green alga Microcystis aeruginosa. Aust $\mathcal{f}$ Biol $S_{c i}$ 1981;34:179-87.

5 Slatkin DN, Stoner RD, Adams WH, Kycia JH, Siegelman WH. Atypical pulmonary thrombosis caused by a toxic cyanobacterial peptide. Science 1983;220:1383-5.

(Accepted 7 February 1990)
Atkinson Morley's

Hospital, London SW20 ONE

John Kew, MRCP, neurological registrar Maurice Gross, FRCP, consultant neurologist

Ashford Hospital, Ashford, Middlesex

Patrick Chapman, FRCS, consultant ear, nose, and throat surgeon

Correspondence to: Dr J Kew, 33 Bexley Court, Parkside Road, Tilehurst, Reading RG3 2DY.

BrMed J 1990;300:1441

\section{Shy-Drager syndrome presenting as isolated paralysis of vocal cord abductors}

\section{John Kew, Maurice Gross, Patrick Chapman}

The Shy-Drager syndrome (multiple system atrophy with autonomic failure) is now recognised as a rare cause of respiratory stridor due to paralysis of the abductors of the vocal cords. Characteristically, this occurs late in the disease, after patients have developed features of autonomic failure, parkinsonism, and cerebellar ataxia. ${ }^{\prime}$ We report a case of Shy-Drager syndrome in which paralysis of the abductors of the vocal cords preceded the development of other features of the disease by 20 months.

\section{Case report}

A 61 year old woman presented to the ear, nose, and throat clinic in November 1987 with a 12 month history of increasing nocturnal stridor and exertional dyspnoea. Indirect laryngoscopy showed bilateral paralysis of abduction of the vocal cords, but no cause for this could be found despite full investigation including computed tomography of the neck and base of the skull. After an elective tracheostomy she remained well, although regular follow up examinations showed no recovery of the function of the vocal cords.

In January 1989 she presented to the neurology clinic with a six month history of progressive unsteadiness of gait and dysarthria. She had also complained of frequency and urgency of micturition and dribbling urinary incontinence. This had been investigated by urodynamic studies, which had shown a poorly contracting bladder with a residual volume of $400 \mathrm{ml}$. There was no other important history, and she was not taking any drugs.

Examination showed her to be alert with normal intellectual function. Supine blood pressure was $145 / 75 \mathrm{~mm} \mathrm{Hg}$ and standing blood pressure $115 / 65 \mathrm{~mm}$ $\mathrm{Hg}$. The optic fundi were normal. She had a scanning dysarthria and first degree horizontal nystagmus in both directions of lateral gaze. There was no dysphonia. Her arms and legs showed normal power, but tone was increased in the left leg. The tendon reflexes were pathologically brisk, and the left plantar response was extensor. She had ataxia and dysmetria of her arms and legs with mild bilateral intention tremor and dysdiadochokinesia. Sensory examination yielded normal findings. Her gait was broad based, veering, and ataxic, and she was unable to walk heel to toe. There was no rombergism.

Results of haematological and biochemical investi- gations, including erythrocyte sedimentation rate, thyroid function tests, serum vitamin B12 and folate concentrations, and plasma protein electrophoresis, were normal. A test for antinuclear factor and the Venereal Disease Research Laboratory test gave negative results. A chest $x$ ray film did not show any evidence of a neoplasm. An electrocardiogram showed normal $\mathrm{R}-\mathrm{R}$ interval variation $(>10 \%)$ during deep breathing. Examination of cerebrospinal fluid yielded entirely normal findings, and the results of cytologica examination of cerebrospinal fluid were negative. Computed tomography of the brain showed mild generalised cerebral atrophy with more pronounced atrophy of the cerebellum.

\section{Comment}

The clinical features of this case, which included cerebellar ataxia, postural hypotension, and disturbed function of the urinary sphincter, are consistent with the Shy-Drager syndrome. ${ }^{12}$ The syndrome consists of a progressive panautonomic failure with later development of parkinsonian features and cerebellar disturbance.

It is well established that patients with the syndrome may develop stridor and respiratory failure later in the disease because of bilateral paralysis of the abductors of the vocal cords. In one study, eight of 12 unselected patients developed this complication, five of whom needed elective tracheostomy.' One of the patients developed severe stridor and respiratory failure at an early stage of the disease before evidence of extrapyramidal or cerebellar disease. In a clinicopathological study of three patients with multiple system atrophy and paralysis of the laryngeal abductors pronounced selective atrophy of the posterior cricoarytenoid muscles was found at necropsy. ${ }^{3}$ Denervation atrophy of these muscles was seen in two of the three cases, but no evidence of primary neuronal degeneration was found in the nucleus ambiguus, the motor nucleus to the laryngeal musculature. The pathogenesis of the paralysis of the abductors of the vocal cords therefore remains unclear.

The case reported here shows that paralysis of the laryngeal abductors can be the first sign of the ShyDrager syndrome and may precede the development of other features of the syndrome by some timein this case 20 months. We therefore propose that the syndrome should be considered in cases of stridor caused by apparently isolated paralysis of the abductors of the vocal cords.

\footnotetext{
Williams A, Hanson D, Calne DB. Vocal cord paralysis in the Shy-Drager syndrome. I Neurol Neurosurg Psychiatry 1979;42:151-3.

2 Shy GM, Drager GA. A neurological syndrome associated with orthostatic hypotension. Arch Neurol 1960:2:511-27.

3 Banniser R, Gibson W, Michacls L, Oppenheimer DR. Laryngeal abductor paralysis in multiple svstem atrophy. Brain 1981;104:351-68.

(Accepted 20 March 1990
} 